\title{
Emerging Insights of Health Informatics Research: A Literature Analysis for Outlining New Themes
}

\author{
Shah J Miah \\ Victoria University, Melbourne, Australia \\ shah.miah@vu.edu.au \\ Jun Shen \\ University of Wollongong, NWS, Australia \\ John Lamp \\ Deakin University, Geelong, Australia

\section{Don Kerr} \\ University of the Sunshine Coast, Queensland, Australia \\ John Gammack \\ Zayed University, Abu Dhabi, UAE
}

\section{Abstract}

This paper presents a contemporary literature review to provide insights into the current health informatics literature. The objective of this study is to identify emerging directions of current health informatics research from the latest and existing studies in the health informatics domain. We analyse existing health informatics studies using a thematic analysis, so that justified sets of research agenda can be outlined on the basis of these findings. We selected articles that are published in the Science Direct online database. The selected 73 sample articles (published from 2016 to 2018 in premier health informatics journals) are considered as representative samples of health informatics studies. The analysis revealed ten topic areas and themes that would be of paramount importance for researchers and practitioners to follow. The findings provide an important foundational understanding for new health informatics studies.

Keywords: Health Informatics; Healthcare Information Systems; Medical Informatics; IS Research

\section{Introduction}

Health Informatics has experienced rapid research growth and application over the past few decades. As a subset of information systems research, the health informatics is a pivotal area, located at the intersection of information technologies, computer science, social science, behavioural science and health or medical care practices. These multidisciplinary fields are entangled in many forms of problem solving or information processing purposes, in order to meet the demands of various practitioners in the healthcare sectors. This applied research field focuses on key techniques, methods, resources, interventions, and devices that are required to improve data acquisition, retrieving, analysing, processing, displaying and use of information in health and medical decision making. Health informatics is mainly powered by various forms of information technologies, Internet enabled technologies, communication technologies, mobile or hand-held device based functionalities and telecommunication infrastructures, systems and their practices (Mosa, Yoo and Sheets, 2012). This health information, as a multi-disciplinary field, is well-known due to its coverage as a wider 
spectrum of its many sub-fields that combine the problem-solving skills of computer scientists or information systems specialists offering benefits to health care organisations and professionals or health care givers.

The main aims of designing health informatics solutions are to deliver appropriate and innovative applications and technologies for improving healthcare information delivery. While the field is rapidly growing due health informatics has become an umbrella term that can be defined in the context of electronic health (e-health) research, clinical decision support systems (CDSS), mobile health, electronic government for healthcare and telehealth (Wang, Turner and Scott, 2003). This implies that scope of health informatics research is going beyond the health information products, systems and services, including tools for health practitioners and different users groups as well as personalised healthcare or monitoring systems for patients and citizens (European Commission, 2004), as it can be related to any healthcare service delivery methods such as video conferencing, file sharing, blogging, and social media data exchange.

Health Informatics has also been defined by World Health Organisations as an umbrella term and defined it to "encompass the rapidly evolving discipline of using computing, networking and communications - methodology and technology - to support the health related fields, such as medicine, nursing, pharmacy and dentistry" (Al-Shorbaji, 2001, p. 2). Although vital research attention through a systematic literature review has been experienced over the past decades in the field, studies identifying themes as future research directions from existing research has been somehow limited. Ikram, Ghani and Abdullah (2015) conduced a systematic literature review to analyse the application of health informatics in the four traditional medicine systems - Chinese Medicine, Ayurveda, Traditional Arabic and Islamic Medicine and Traditional Malay Medicine. The study by Ikram et al. (2015) utilised four databases (such as Ebsco Host, IEEE Explore, Proquest and Google scholar) finding the terms such as "Traditional Medicine", "informatics", "informatics infrastructure", "traditional Chinese medicine", "Ayurveda", "traditional Arabic and Islamic medicine", and "traditional Malay medicine". Based on the combination of the search terms, the study explored the involvement of informatics as a modern medicine system. Deng et al (2018) produced a literature review that analysed existing medical informatics research by Chinese academics on their articles published in international specialty journals. The main purpose of that study was to summarize the experiences and lessons learned in the medical informatics field. Our aim differs from these works as we focus on revealing insights through exploring their themes that constitute essential knowledge for researchers and practitioners in the health informatics field.

In our study, we analyse existing health informatics studies to reveal insights using a thematic analysis, so that we can outline research agenda for this special section, based on findings of that analysis. We selected articles that are published in Elsevier's Science Direct database ${ }^{1}$ (from 2016 to 2018) searching complete research and review articles from premier health informatics journals. The selected 73 sample articles are considered to be representative of health informatics field.

This review paper is structured as follows: the next section describes the background of the study while the section 3 describes the methodological details. The section 4 presents the findings of the literature review through using the thematic analysis. The section 5 describes

\footnotetext{
1 https://www.sciencedirect.com/
} 
the selected articles published in the special section and further studies in the field. Finally, the section 6 provides a discussion and summarises of the selected manuscripts.

\section{Background of the research field}

The term "health informatics" has been an umbrella concept used interchangeably with healthcare informatics, medical informatics, and biomedical informatics. This field has been defined as information engineering for healthcare or medical care benefits essentially the patient healthcare and its management, through the application of various information technologies. Nadri et al. (2017) described that healthcare informatics is a multidisciplinary field that uses health information technologies in order to improve healthcare services via any combination of higher quality, higher efficiency as well as for creating new opportunities. The multidisciplinary field included information sciences, social, management, behavioural and other artificial sciences. O'Donoghue and Herbert (2012) argued that this multidisciplinary field deals with the resources, devices, and methods required to "optimize the acquisition, storage, retrieval, and use of information in health and bio-medicine. Health informatics tools include computers, clinical guidelines, formal medical terminologies, and information and communication systems" (p.2). This implies that the research has been diversified in providing different healthcare or medical information support services.

Gardner et al. (2009) identified various concerns with the use of information technologies in healthcare by or for clinicians or practitioners. Clinical or medical practitioners mainly aim to transform healthcare service by analysing, designing, implementing, and evaluating health information for better clinical and non-clinical outcome. The purposes of health informatics tools or applications were defined to 1) assess information and knowledge needs of practitioners, patients and communities; 2) characterize, evaluate, and refine clinical processes; 3) develop, implement, and refine clinical decision support systems; and 4) lead or participate in the procurement, customization, development, implementation, management, evaluation, and continuous improvement of clinical information systems.

Clinicians or medical practitioners collaborate with other health and information technology professionals to develop health informatics tools which promote patient care that is safe, efficient, effective, timely, patient-centred, and equitable. Mobile health approaches are one of the popular effective provisions of health informatics research. M-health broadly refers to a mobile service or application for providing healthcare support to anyone, anytime, and anywhere (Miah, Gammack, Hasan, Hasan, 2016). Utilising the processing power of mobile phones, GPRS and Internet technologies, M-health provides health professionals, patients, clinicians and other relevant users with support services to manage, disseminate, collect, administer, control and monitor healthcare information and improve health service delivery and quality of care support. The service provided by various $\mathrm{m}$-health information systems (IS) applications, eliminates geographical and temporal constraints while enhancing the coverage, quality, cost savings and other user provisions of healthcare (Varshney, 2014; Miah et al. 2017). As a sub-class of IS, clinical decision support systems (CDSS) are a type of specialised DSS application that directly aids in "clinical decision making in which characteristics of individuals are matched to a computerized knowledge base for the purpose of generating patient-specific recommendations (Hunt et al. 1998). Combining these, Mobile decision support applications have been developed for supporting decision making in clinical and non-clinical settings. These studies developed over the past decade have been viewed into three groups: 1) mobile based CDSS for physicians and healthcare professionals (e.g. Martínez- 
Pérez et al. 2014; Karim and Bajwa, 2011);2) mobile based decision support for outreach health workers (e.g. Parveen et al. 2014; Kuntagod and Mukherjee, 2011); and 3) mobile based decision support for public use or improving public healthcare (e.g. Ramesh et al. 2012; Fung et al. 2014).

The health informatics field has been extended over past decades to cover many directions in information systems. The sub-fields are healthcare service delivery technologies, data acquisition for healthcare or medical support; knowledge management for healthcare users, decision support systems for healthcare and medical purposes, healthcare modelling and simulation; data analytics, various health information systems, clinical information systems, integrated data repository, and computational intelligence for health care applications.

Hence, it is an essential task to provide a summary to determine the various paths of accumulated knowledge for IS researchers within the area of health informatics using an application oriented perspective to provide a better understanding of the sub-field. A contemporary review discussion can offer such an overview on how the sub-field is creating an impact within the research field. It would also be an important reading for current practitioners and research students within the field. It can provide clearer understanding on the progressions of sub-fields within the field of health informatics. As such, the main aim of this study is to address the following research question: What are the current research themes in the existing health informatics studies that show promise for future knowledge growth?

\section{Study Methodology}

In IS research, a systematic literature review (SLR) has been one of the popular methodologies used to reveal generalisable insights and themes that may help to create better understanding in shaping or developing an overview of a sub-field's body of knowledge. Webster and Watson (2002) have indicated productive directions of conducting an SLR that may contribute to IS research and practice for preparing better future of the discipline. SLRs not only organise cognate studies but can also sustain the evolution of evidence-based guidelines for practitioners (Brereton et al. 2007). Thus, we use the SLR approach to derive deeper understanding of existing health informatics research following Brereton et al.'s (2007) three phases of Planning (defining research question and protocol), Conducting (identify and assess relevant studies) and finally Document Review, where the synthesis of findings is written up.

Our main purpose is to gain insights related to the identification of themes in developing health informatics solutions both for organisations and practitioners. Our scope includes health (healthcare, clinical, non-clinical or public healthcare delivery atmospheres) informatics research covering literature reviews, theoretical research, practical problem solving research, case studies, and/or any other forms of qualitative, quantitative and mixed methods or approaches in the relevant field. We have followed a bottom-up approach for collecting sample articles that took a multi-disciplinary perspective and were published as a fullresearch article at the Elsevier database driven by Science Direct.

The search was performed across Science Direct (figure 1) identifying papers between 2016 to till 15 Nov 2018. Simultaneously we searched "health informatics" and "healthcare analytics" to capture articles that have the keyword in title, abstract, or body of the paper in order to 
satisfy PRISMA 2 conditions. Search strings defined subjectively (Jamshidi, Ghafari, Ahmad, and Pahl, 2012) were applied to the database, comprising the terms \{“health" or "healthcare"\} and \{"informatics" or "Informatics"\}, aiming to return the greatest volume of relevant articles. After that we excluded articles not in English, published in abstract, mini-reviews, editorial, news and also book chapters, newspaper articles, unpublished thesis papers and non-scientific articles.

Initially, we assessed titles and applied the pre-defined inclusion and exclusion criteria to each articles, obtaining a set of potentially relevant sample articles. Following this, the full text of each article was obtained and their contents were critically evaluated by team members manually reading each article. 1,388 freely available articles were then selected for initial sorting. After removing duplicates, and those not satisfying our research foci, we came up with 112 articles. Finally, after coding we excluded another 39 papers inappropriate to addressing our research question resulting in 73 papers selected for review.

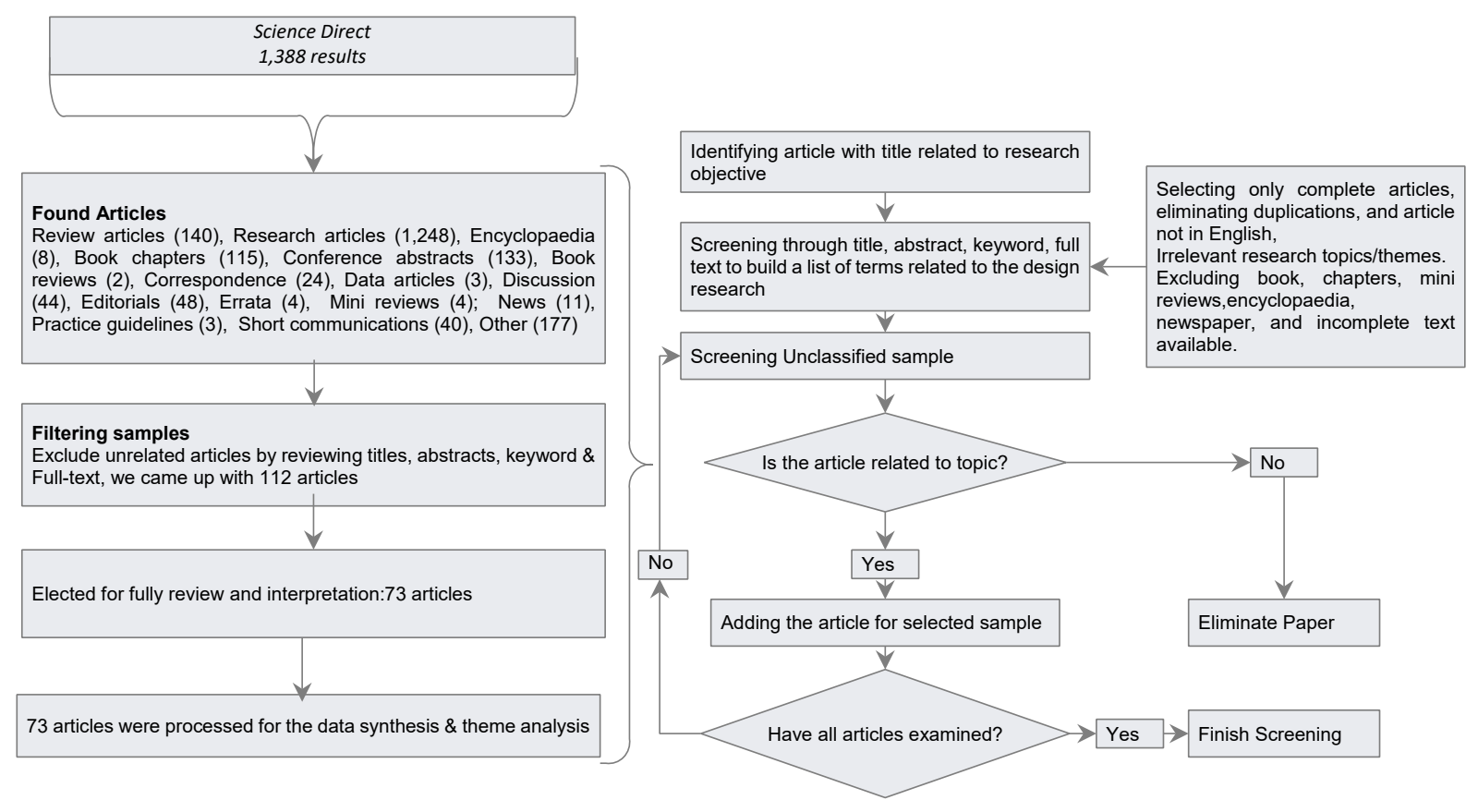

Figure 2: SLR Methodology for sample collection

2 PRISMA provides guidance on evidence-based minimum sets of items required for conducting systematic literature reviews. PRISMA targets healthcare meta-analyses, but can also be used as a basis for reporting review findings. 

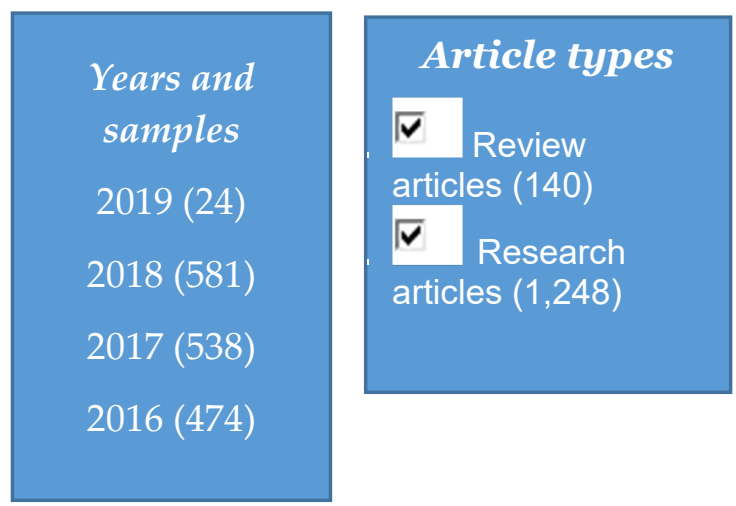

Journal names and No. of

articles

Procedia Computer Science (128)

International Journal of Medical

Informatics (102)

Journal of Biomedical Informatics

(64)

The Lancet (31)

Future Generation Computer Systems (28)

Journal of the Academy of Nutrition and Dietetics (28)

IFAC-Papers Online (25)

Neuro computing (24)

Journal of Clinical Epidemiology

(17)

Computers in Biology and Medicine

(16)

Figure 3: Descriptions of sampling sources

\subsection{Thematic Analysis}

Thematic analysis is a technique for classifying, distinguishing, analysing and summarizing themes from the available data. It systematizes and defines the data set from details (Boyatzis, 1998). One of the advantages of using thematic analysis is that it provides a flexible approach to identifying themes and thus provides a more accessible and useful form of analysis (Nowell, Norris, White, \& Moules, 2017). In addition, thematic analysis allows researchers to generate unanticipated insights based on the themes produced. Nowell et al. (2017) described thematic analysis as a useful method for summarizing large sets of data through a well-structured approach to handling information. Therefore we decided to adopt the approach of thematic analysis by Braun and Clarke (2006) in which the six-step phases seemed helpful for analysing the sample articles. These steps are: 1 ) familiarisation with the data; 2 ) generating initial codes; 3) searching for themes; 4) reviewing themes; 5) defining and naming themes, and 6) producing the report. In our study, as a part of the step 1, we found 73 sample articles published in the last five years regarding various directions of health informatics. During step 2 of the analysis, we coded each selected article. As part of step 3, we identified key themes and generated some descriptions around the themes from the target topic area. As part of reviewing the themes in step 4, we classified those themes with some additional details collected from those research articles. In step 5, we named ten themes as being key, and reviewed each theme three times to determine the aspects that each theme contributed. Finally in step 6, to produce a concise and logical analysis oriented towards future developments, we present ten key themes in Table 1. 


\section{Findings}

We found that health informatics research has been extended in application areas such as pathology, medical imaging, public healthcare, community care, home care, nursing, medical practices, consumer healthcare, clinical and bioinformatics, and clinical research domains. The application of the latest mature technologies are established in these domains but there are other technologies which are still in an embryonic stage. This implies that theory development research is still in demand to guide future application development research. Further research should also be encouraged to assist with the maturing of existing areas in the field.

We have consolidated ten key themes that show paths for the further growth and progress of research within the heath informatics field. A major concern of our thematic analysis was to determine underlying technological developments and their target application areas to identify sub-fields for improvement. This would identify the relevance or future research in the field of health informatics. In our presentation of these themes we include a description of the identified themes based on perceived significance. The first three topics are big data, telemedicine \& telecare, and digital healthcare service delivery. Table 1 illustrates the details of our initial findings.

\begin{tabular}{|c|c|c|}
\hline Theme & Summary of findings & Comments \\
\hline Big Data & $\begin{array}{l}\text { The review found highest number of articles were published on big } \\
\text { data. For instance, data analytics frameworks for prediction analysis is } \\
\text { common in examining a big health dataset. Mahmud, Iqbal and Doctor } \\
\text { (2016) described a big data analytics framework that is based on a } \\
\text { cloud computing integrated to GIS and smart devices for capturing and } \\
\text { visualising big data. The research was supported with a predictive } \\
\text { model for health-shocks, using data from } 1000 \text { households in rural } \\
\text { accessible regions of Pakistan. } \\
\text { Nair et al. (2018) described a big data enabled system that aims at } \\
\text { developing a health status prediction approach that using big data } \\
\text { processing focusing on applying a machine learning model. } \\
\text { Choudharya and Bajaj (2015) introduced data analytics using data } \\
\text { mining techniques to be implemented on a rapid mining tool, so that } \\
\text { diseases can be detected. The authors used a classification technique } \\
\text { based on cross validation and decision trees to detect records before } \\
\text { seeking advice from the doctor. Also, Rallapalli et al. (2016) described } \\
\text { the impacts of data processing and analysing big healthcare data } \\
\text { generated in the cloud computing environment for better decision } \\
\text { making. To analyse the large-scale data they source automatically } \\
\text { collected data from various healthcare applications and devices. To } \\
\text { achieve better performance and to solve the scalability issues it is } \\
\text { important to have a distributed big data system for handling data } \\
\text { diversities of a cloud environment. }\end{array}$ & $\begin{array}{l}\text { Our thematic } \\
\text { analysis revealed } \\
\text { that big data issues } \\
\text { in health informatics } \\
\text { have been an } \\
\text { important area that } \\
\text { show promise for } \\
\text { future knowledge } \\
\text { growth in the field. } \\
\text { Different analytics } \\
\text { solutions using } \\
\text { cloud computing as } \\
\text { a method of } \\
\text { solution, is one of } \\
\text { the active existing } \\
\text { themes, while other } \\
\text { types of studies such } \\
\text { as analysing various } \\
\text { contexts of big data } \\
\text { and their impacts for } \\
\text { designing } \\
\text { technological } \\
\text { solutions are still at } \\
\text { embryonic stage in } \\
\text { development. }\end{array}$ \\
\hline
\end{tabular}




\begin{tabular}{|c|c|c|}
\hline Theme & Summary of findings & Comments \\
\hline $\begin{array}{l}\text { Telemedicine, } \\
\text { Telecare and } \\
\text { Telematics }\end{array}$ & $\begin{array}{l}\text { The review found the second highest number of articles was published } \\
\text { on telemedicine and telecare themes. For instance, Faiola and Holden } \\
\text { (2017) addressed ways people are increasingly moving to healthy living } \\
\text { medicine (HLM) to mitigate health threats. HLM-seeker citizens } \\
\text { rapidly adopted mobile technologies that enable control of personal } \\
\text { healthcare as well as for collaboration with clinicians or other } \\
\text { healthcare agents in order to have effective healthy living practices. } \\
\text { These types of technologies are helpful with interventions such as } \\
\text { medication and surgery with possible further risk of adverse effects, if } \\
\text { there are risks from complex diseases and poor health habits. Another } \\
\text { example study is that of Lilholt et al. (2015) in which a telehealth } \\
\text { system was developed and its usability was evaluated for Danish } \\
\text { TeleCare North. The study used domain experts and principles, and } \\
\text { compliance with Jakob Nielsen's ten usability heuristics for interaction } \\
\text { design. }\end{array}$ & $\begin{array}{l}\text { Our thematic } \\
\text { analysis revealed } \\
\text { that telemedicine } \\
\text { and telecare topics in } \\
\text { health informatics } \\
\text { have been another } \\
\text { significant topic area } \\
\text { that show promises } \\
\text { for future } \\
\text { knowledge growth } \\
\text { in the field. }\end{array}$ \\
\hline Digital health & $\begin{array}{l}\text { The review found the third highest number of articles published in } \\
\text { relation to broader digital health topic areas. Alshagathrh et al. (2018) } \\
\text { described the experience of building an implantable medical device } \\
\text { registry in Saudi Arabia. The work specifically addressed the early } \\
\text { experiences of the Saudi Food and Drug Authority in developing a data } \\
\text { sharing model for the implementation of a medical device registry at } \\
\text { different hospitals. Miah, Hasan, Hasan and Gammack (2017) } \\
\text { described a mobile health solution for the purpose of rural citizens' } \\
\text { healthcare decision support and information dissemination and also for } \\
\text { diabetics management support care (Miah, Hasan and Gammack, } \\
\text { 2016). The other study by Qi et al. (2015) explored the current situation } \\
\text { and issues related to the development of the public healthcare } \\
\text { workforce system for disease control and prevention in China. After } \\
\text { identifying issues through the use of a survey, the study described } \\
\text { corresponding strategies to address these issues for the future. }\end{array}$ & $\begin{array}{l}\text { Our thematic } \\
\text { analysis revealed } \\
\text { that broader digital } \\
\text { health topics in } \\
\text { health informatics } \\
\text { have been another } \\
\text { significant topic area } \\
\text { that shows promise } \\
\text { for future } \\
\text { knowledge growth } \\
\text { in the field. }\end{array}$ \\
\hline Education & $\begin{array}{l}\text { The review found the fourth highest number of articles were published } \\
\text { in relation to education in health information systems areas. For } \\
\text { example, Chonsilapawit and Rungpragayphan (2016) described the } \\
\text { assessment of Thai hospital pharmacists' skills and knowledge of } \\
\text { informatics, and their training needs, in order to improve curricular } \\
\text { and professional development. The most current pharmacy curricula in } \\
\text { Thailand barely address the principles and skills concerned with } \\
\text { informatics, and Thai pharmacists usually acquire computer literacy } \\
\text { and informatics skills through personal-interest, training and self- } \\
\text { study. Another example study by Deng et al. (2018) analysed the } \\
\text { quality and quantity of research by Chinese academics in medical } \\
\text { informatics based on their articles published in international specialty } \\
\text { journals in recent years and examined medical informatics research } \\
\text { hotspots in China. }\end{array}$ & $\begin{array}{l}\text { Our thematic } \\
\text { analysis revealed } \\
\text { that health } \\
\text { informatics has } \\
\text { become an } \\
\text { important subject of } \\
\text { teaching and } \\
\text { learning which is } \\
\text { being developed in } \\
\text { many Asian } \\
\text { countries. There is a } \\
\text { need for developing } \\
\text { research in relevant } \\
\text { pedagogies for better } \\
\text { practices in health } \\
\text { informatics } \\
\text { education. }\end{array}$ \\
\hline
\end{tabular}




\begin{tabular}{|c|c|c|}
\hline Theme & Summary of findings & Comments \\
\hline Smart living & $\begin{array}{l}\text { The review found a number of articles published in relation to smart } \\
\text { living topics in health informatics literature. This areas addressed smart } \\
\text { technologies including Internet of Things based interventions. For } \\
\text { instance, Sun et al. (2018) introduced a data sensor model for an obesity } \\
\text { identification, analysis, and estimation in which user is regarded as an } \\
\text { online social network 'sensor' that can provide valuable health } \\
\text { information. da Costa et al. (2018) developed an approach (enabled by } \\
\text { the Internet of Things) for allowing data from different sources to be } \\
\text { combined in order to better diagnose patient health status and identify } \\
\text { possible anticipatory actions. Then other example study by Phan et al. } \\
\text { (2017) described research problems with human behaviour prediction } \\
\text { and suggested explanations of healthcare intervention systems in } \\
\text { health social networks, proposing an ontology-based deep learning } \\
\text { model. Yoshiura et al. (2018) proposed a health observatory conceptual } \\
\text { model based on the Semantic Web in order to assist in the design, } \\
\text { development and implementation processes of a Health Observatory. }\end{array}$ & $\begin{array}{l}\text { This shows that } \\
\text { smart systems have } \\
\text { experienced initial } \\
\text { hype and later } \\
\text { maturity periods in } \\
\text { the path to better } \\
\text { adoption and } \\
\text { acceptance, with a } \\
\text { focus on realistic } \\
\text { solutions with } \\
\text { combination of } \\
\text { emerging } \\
\text { technologies to } \\
\text { improve IT enabled } \\
\text { health care. }\end{array}$ \\
\hline $\begin{array}{l}\text { Ethics, } \\
\text { privacy, } \\
\text { security and } \\
\text { other concerns }\end{array}$ & $\begin{array}{l}\text { The review found a number of articles published in relation to ethics, } \\
\text { privacy and security topic areas in health informatics. For instance, } \\
\text { Valdez and Ziefle (2018) described the importance and utility of } \\
\text { privacy-preserving techniques related to sharing of personal health } \\
\text { data and differential privacy, analysing different sharing scenarios } \\
\text { depending on the recipient of the data, the benefit of sharing data, the } \\
\text { type of data, and parameterized privacy. Nguyen et al. (2017) described } \\
\text { a survey study to determine the prevalence and predictors of access to } \\
\text { the Internet and use of the Internet to search for health information. } \\
\text { Shin et al. (2017) presented a study that validated a model using data } \\
\text { collected in a time-series study of consumer use of online HIS in a user } \\
\text { oriented context. Richardson et al. (2017) described further } \\
\text { determinants of usability, evaluating types of additional information } \\
\text { gained from specific usability testing, considered as a part of the } \\
\text { development phase of an integrated clinical prediction rule. Roman et } \\
\text { al. (2016) described a literature review study to assess the prevalence of } \\
\text { navigation-related topics within the EHR usability and safety. }\end{array}$ & $\begin{array}{l}\text { This shows that the } \\
\text { majority of the } \\
\text { studies did pay } \\
\text { attention to the } \\
\text { importance of issues } \\
\text { in ethics, privacy } \\
\text { and security. Health } \\
\text { informatics is a } \\
\text { major field where } \\
\text { these concerns are } \\
\text { extensively } \\
\text { investigated, }\end{array}$ \\
\hline Aged care & $\begin{array}{l}\text { The review found a number of articles published in relation to age care } \\
\text { in health informatics topic areas. For example, Faiola, Papautsky and } \\
\text { Isolawe (2018) described an m-health lifestyle management model that } \\
\text { utilises mobile health technology as a means to engage the baby } \\
\text { boomer generation consumers in ways that establish the ageing } \\
\text { population's self-care. Queiros et al. (2017) described a synoptic } \\
\text { overview of current research into mobile health applications for ageing. } \\
\text { The study found that a considerable number of mobile health } \\
\text { applications for the ageing population have been developed for } \\
\text { example supporting the care of patients with chronic medical } \\
\text { conditions, promoting healthy lifestyles, minimizing loneliness and } \\
\text { social exclusion, and ensuring home safety. This shows that aged care } \\
\text { has been supported with mobile health services to meet real needs. }\end{array}$ & $\begin{array}{l}\text { This shows that the } \\
\text { research on } \\
\text { improving lifestyle } \\
\text { of ageing } \\
\text { populations has } \\
\text { been growing and } \\
\text { there is a need for } \\
\text { improving literature } \\
\text { on ageing care and } \\
\text { support for their } \\
\text { self-management } \\
\text { and independent } \\
\text { support. }\end{array}$ \\
\hline
\end{tabular}




\begin{tabular}{|c|c|c|}
\hline Theme & Summary of findings & Comments \\
\hline $\begin{array}{l}\text { Clinical and } \\
\text { decision } \\
\text { support } \\
\text { (CDSS) aspects }\end{array}$ & $\begin{array}{l}\text { The review found a number of articles published in relation to clinical } \\
\text { decision support (CDSS) topic areas. For example, Kocbek et al. (2016) } \\
\text { described a text mining based CDSS for detecting admissions marked } \\
\text { as positive for several diseases: Lung Cancer, Breast Cancer, Colon } \\
\text { Cancer, Secondary Malignant Neoplasm of Respiratory and Digestive } \\
\text { Organs, Multiple Myeloma and Malignant Plasma Cell Neoplasms, } \\
\text { Pneumonia, and Pulmonary Embolisma. The study used Support } \\
\text { Vector Machine classifiers for analysing the data from a combination of } \\
\text { sources of medical records. Robinson et al. (2014) identified the } \\
\text { importance of patient portals for patients' interaction with healthcare } \\
\text { organizations and to view information. The purposes are categorised as } \\
\text { informational, medical, logistical, or social. da Costa et al. (2018) } \\
\text { developed an approach (enabled by the Internet of Things) for allowing } \\
\text { data from different sources to be combined in order to better diagnose } \\
\text { patient health status and identify possible anticipatory actions. The DSS } \\
\text { research is also rapidly growing in other health oriented fields such as } \\
\text { for healthcare supply chain (Miah, Ahsan Msimangira, 2013; Miah, } \\
\text { 2008) }\end{array}$ & $\begin{array}{l}\text { This shows that the } \\
\text { majority of the CDSS } \\
\text { studies focused both } \\
\text { on clinical and non- } \\
\text { clinical context for } \\
\text { the purpose of } \\
\text { decision making. }\end{array}$ \\
\hline $\begin{array}{l}\text { Organisational } \\
\text { issues }\end{array}$ & $\begin{array}{l}\text { The review found a number of articles published in relation to } \\
\text { organisational issues as topic areas. For example, Garmann-Johnsen } \\
\text { (2015) compared two European regions on their use of assistive } \\
\text { technologies. } \\
\text { Miah, Hasan and Gammack (2016) developed a cloud based e-heath } \\
\text { solution for government to help bridging the digital divide between } \\
\text { rural and urban healthcare services, enabling provision of suitable } \\
\text { medical diagnoses and treatment consultations in a developing } \\
\text { country. Other example study by Carney and Kong (2017) investigated } \\
\text { a phenomena of the complex problem of HIS design. The study } \\
\text { suggested a collective response that may offer intelligence for an } \\
\text { effective knowledge ecosystem, enhanced health informatics capacities, } \\
\text { knowledge exchange, big-data, and situational awareness } \\
\text { demonstrating the complex problems for the health informatics } \\
\text { professionals. Another study by Miah, Hasan, Hasan and Gammack } \\
\text { (2017) introduced a social media based CDSS to provide appropriate } \\
\text { end-user technology (e.g. open media) that generally design based on } \\
\text { real users' demand using information systems development method } \\
\text { that contribute principled specifications of design knowledge. }\end{array}$ & $\begin{array}{l}\text { This shows that the } \\
\text { majority of the } \\
\text { organisational issues } \\
\text { studies focused both } \\
\text { on clinical and non- } \\
\text { clinical context for } \\
\text { the purpose of } \\
\text { healthcare } \\
\text { information system } \\
\text { development and } \\
\text { implementation. }\end{array}$ \\
\hline $\begin{array}{l}\text { Evaluation } \\
\text { and impact } \\
\text { analysis }\end{array}$ & $\begin{array}{l}\text { The review found a number of articles published in relation to } \\
\text { evaluation and impact analysis in health informatics. For example, } \\
\text { Brown et al. (2017) described an evaluation of a new HIS called "e- } \\
\text { A\&F" for primary care (the Performance Improvement plaN } \\
\text { GeneratoR; PINGR). The system covers the aspects of clinical } \\
\text { performance, patient lists, patient-level data, and recommended actions } \\
\text { and for evaluation, the study used iterative approach involving } \\
\text { multiple evaluation cycles at different stages. Another example study } \\
\text { by Craig and Kodate (2018) contributed to literature of socio-technical } \\
\text { theory and its value and/or relevance to health information in Ireland. } \\
\text { The study focused on three factors that can impact on health } \\
\text { information; those of policy, infrastructure and people (PIP), examining } \\
\text { how Ireland compares with other countries in relation to these factors. }\end{array}$ & $\begin{array}{l}\text { This shows that the } \\
\text { majority of the } \\
\text { evaluation and } \\
\text { impact analysis in } \\
\text { health informatics } \\
\text { focused both on } \\
\text { clinical and non- } \\
\text { clinical context for } \\
\text { the purpose of HIS } \\
\text { implementation. }\end{array}$ \\
\hline
\end{tabular}

Table 1: Findings of the health informatics literature review, with comments on each aspect. 


\section{Special Issues and Further Extended Avenues}

From the ten key themes, we raised a call for new research papers that promote health informatics research. Our aim was to stimulate the field by encouraging more contemporary studies that are needed to fill knowledge gaps. In September 2017 we published this call for a special section in the Australasian Journal of Information Systems. In total, sixteen articles were received. Four were declined as they were irrelevant to the special section's area of interest. Twelve articles were selected for peer review. After conducting three review cycles, only six articles were finally accepted for publication in the special section. A key similarity of these articles' focus is that each study examined effective health informatics research for organisations and stakeholders. The details of the published articles are given below.

Article 1: Tele-monitoring Technology as a Tool for Monitoring and Management of Patients with Congestive Heart Failure

Telehealth interventions are designed to facilitate the remote exchange of information and data between patients and health care providers, improving the quality and safety of the patients and increasing efficiency and cost-effectiveness of health care providers. The development of telecommunications and virtual technology allowed a number of telehealth systems to be applied in different health care areas. These technologies can provide an alternative monitoring and solutions for decreasing the hospital readmission rates for patients with congestive heart failure $(\mathrm{CHF})$. In this paper, a systematic literature review regarding telemonitoring and its use in the management of patients with CHF is conducted. The result indicated that standardized tele-monitoring design would reduce a length of hospitalization and re-hospitalization rate. The other factors that moderate the effectiveness of the telemonitoring intervention include quality of life, mortality rate, and disease-specific knowledge (health literacy). All these factors align with the consumer-centred principle of The Australian Safety and Quality Framework for Health Care.

\section{Article 2: The Experiences of Three Different User Groups Using Personally Controlled Health Record for Multidisciplinary Care Team}

Personally Controlled Health Records (PCHR) are patient-centric tools which allow individuals to own, manage, access and share their health information online from anywhere, at any time. Patient-centric tools have received considerable interest and investment in recent years worldwide. These tools are thought to have the potential to increase individuals' selfmanagement and involvement in their own health, as well as improve healthcare efficiency and delivery. The aim of this study is to report and analyse the experiences of three different user groups using PCHR for Multidisciplinary Care Team (MDCT) including the advantages, disadvantages, barriers and obstacles, and the current state of PCHR. In order to achieve the aim of this study, sixteen interviews with key informants from three different user groups were conducted in Dunedin, New Zealand. Interviews were transcribed and analysed with thematic analysis.

The key findings of this research showed that those who can benefit the most from PCHRs are the least able to use it. It suits those who have basic knowledge about computers and the internet and those who can afford to use them. PCHR is also best suited for individuals who are motivated about their health despite their health condition. However, more research is needed in the future with a larger sample, an easier to use PCHR, different population other 
than community health workers, patients with different chronic illnesses, and healthy patients. This research can be used as a basis and tested in future research on PCHR adoption.

Article 3: The impact of telehealth technology on user perception of wellbeing and social functioning, and the implications for service providers

The aim of the project was to evaluate the use of telehealth equipment in the homes of older community-dwelling people, and to review its social and economic impact. A mixed methods approach was adopted, involving interviews, observation and Depression Anxiety Stress Scales. Overall, the greatest benefit was apparent in those participants with a low familiarity with technology and low digital literacy, where changes in behaviours to prevent an exacerbation of their condition was possible. The user interface design reduced concern about using the technology. Changes achieved were through better compliance with medication and associated understanding of the impact on their vital signs and hence daily activities. This represented an improved health literacy and the economic benefits appear to be linked to that. Less benefit was observed by those who had been self-monitoring previously. A greater focus on specific conditions and improved self-management could strengthen the evidence for targeted economic benefits.

Article 4: Overcoming carer shortages with care robots: Dynamic value trade-offs in run-time

A rising elderly population and diminishing number of family and professional carers has led to calls for the intervention of care robots. This leaves the quality of robot-delivered care to be determined by designers, for profit companies, nursing codes of practice and conduct, potential user sample groups, etc. What is missing is the carer who consciously makes good ethical decisions during practice. Good care is 'determinative in practice'. That is, a carer can make good decisions because they are making them within the carer-patient relationship. If a robot is to be capable of good care ethics on the same level as humans, it needs to be conscious and able to make dynamic decisions in practice. Moreover, a care robot must conduct patient interactions in appropriate ways, tailored to the person in its care, at run-time. This is because good care, as well as being determinative in practice, is tailored to the individual. The introduction of robotic care determined by limited stakeholders leaves customised care in danger and instead could potentially turn the quality of elderly care into 'elderly management'. This study introduces a new care robot framework - the attentive frameworkwhich suggests using care centred value sensitive design (CCVSD) for the design process, as well as a computationally conscious information system (IS) to make practice-determinative decisions in run-time with extrinsic care value ordering. Although VSD has been extensively researched in the IS literature, CCVSD has not. The results of this study suggest that this new care robot framework, which is inspired by CCVSD, is competent in determining good, customised patient care at run-time. The contribution of this study is in its exploration of enduser willingness to trust known AI decisions and unwillingness to trust unknown AI decisions. Moreover, this study signifies the importance of, and desire for, good, customised robot-delivered care.

\section{Article 5: Understanding the Factors that Influence the Primary Appraisal of mHealth Tools in Developing Countries: An Exploratory Case-Study in Nigeria}

Shortages of health workers, infrastructural deficiencies, limited access to medical care are just a few of the many barriers to care in developing countries. The integration of smartphones and mobile devices into healthcare systems has been proposed to address some of the physical 
barriers to care and service delivery. These mHealth solutions extend the reach of medical care into rural areas of developing countries. However, it is not clear how mHealth solutions designed and tested in one developing region can be positively appraised for use in others. This study frames this problem using a coping theory approach based on an exploratory casestudy to understand the factors that influence primary appraisal of smartphone-enabled clinical guidelines (mHealth tool) for accessing, classifying and eliciting treatment recommendation for sick children under the age of five by rural healthcare workers (RHCWs). Findings identified a set of factors which are bound as an emerging explanatory positivity model that influence primary appraisal of an mHealth tool in a new context. These factors are the set of individual and social factors that governments, funding bodies and nongovernmental organisations should consider before embarking on the introduction of an mHealth tool in rural communities of developing countries. It is envisaged that by understanding the factors that influence primary appraisal, that is, either as an opportunity or a threat, practitioners and organisations will support positive appraisal and minimise the occurrence of negative ones when introducing mHealth tools. These findings have implications for theory, practice, and future research as explained in the concluding section of this paper.

\section{Article 6: A Design Construct of Developing Approaches to Measure Mental Health Conditions}

Mental health is an important determinant of communities' well-being, influenced not only by individual attributes, but also by social and organisational environments in which people work and live. Despite studies examining mental health status among specific populations, few attempts are evident that focus on solution designs for detecting and measuring impact of mental health conditions. In this study, we develop a construct utilising design science research principles for outlining common vocabulary around the problem, and solution design relevant to a mental health management system. For the case of IT professionals, the developed construct is informed through a social-media based dataset containing more than 65,000 cells and 100 attributes potentially identifying influencing factors. Machine learning techniques are applied to the dataset to discover new findings for this specific group. It is anticipated that the analysis reported in this study would contribute in developing other electronic health management systems both for communities and healthcare professionals.

\section{Overall Discussion}

In this study, we conduct a systematic review of the literature focusing on determining the key themes of health informatics research. In order to answer the research question: What are the current research themes in the existing health informatics studies that show promise for future knowledge growth? Thematic analysis was the functional choice to explore the major themes in the existing health informatics literature. This analysis method followed an inductive approach for outlining key themes from initial findings from the sample articles. After following the six steps of thematic analysis including re-reading, re-coding, re-focusing, and refining the content of each paper, ten main themes have been identified that were described in Table 1.

This type of research may offer benefits within the field as it offers an indication for future research growth. New or early career researchers can find in this research a landscape for building a foundation of their own study within the health informatics field. Research in the health information domain is not a completely new field, but in this study we reinforce a need 
for substantial exploration and improvement in various emerging sub-fields of the health informatics field, that may provide an insight which motivates researchers and practitioners in the field, by suggesting new research areas on innovative health systems, and their users and the context of their use (such as the key components of technologies, people and organisations). We consider that there is a need for more theoretical and applied research to contribute to the maturity of the health informatics field, which is a significant subset of information systems research.

\section{References}

Alshagathrh, F., Khanb, S.A., Alothmany, N., Al-Rawashdeh, N., Househ, M. (2015). Building a cloud-based data sharing model for the Saudi national registry for implantable medical devices: Results of a readiness assessment, International Journal of Medical Informatics $118,113-119$

Al-Shorbaji, N. (2001). Health and Medical Informatics: Technical Paper WHO Cairo, 2001, Cited in Hussein, S. and khalifa, A. (2011).Biomedical and Health Informatics Education and Research at the Information Technology Institute in Egypt, Yearb Med Inform, 20(01): 161-168

Boyatzis, R. E. (1998). Transforming qualitative information: Thematic analysis and code development: sage.

Braun and Clarke (2006) Braun, V., \& Clarke, V. (2006). Using thematic analysis in psychology. Qualitative research in psychology, 3(2), 77-101.

Brereton, P., Kitchenham, B., Budgen, D., Turner, M., and Khalil, M. (2007). Lessons from applying the systematic literature review process within the software engineering domain, Journal of Systems and Software, 80(4), 571-583.

Brown, B., Balatsoukas, P., Williams, R., Sperrin, M., and Buchan, I. (2017). Interface design recommendations for computerised clinical auditand feedback: Hybrid usability evidence from a research-led system, International Journal of Medical Informatics 94,191-206

Chonsilapawit, T. and Rungpragayphan, S. (2016). Skills and knowledge of informatics, and training needs of hospital pharmacists in Thailand: A self-assessment survey, International Journal of Medical Informatics, 94, 255-262

Choudharya, K. and Bajaj, P. (2015). Automated Prediction of RCT (Root Canal Treatment) Using Data Mining Techniques: ICT in Health Care, Procedia Computer Science 46, 682 $-688$

Craig, S. and Kodate, N. (2018). Understanding the state of health information in Ireland: A qualitative study using a socio-technical approach, International Journal of Medical Informatics, 114, 1-5

da Costa, C.A., Pasluost, C.F., Eskofier, B., da Silva, D.B., and Righia, R.D.R. (2018). Internet of Health Things: Toward intelligent vital signs monitoring in hospital wards, Artificial Intelligence In Medicine, 89, 61-69

Deng, H., Wang, J., Liu, X., Liu, B., and Lei, J. (2018). Evaluating the outcomes of medical informatics development as a discipline in China: A publication perspective, Computer Methods and Programs in Biomedicine, 164, 75-85. 
European Commission (2004). eHealth - making healthcare better for European citizens: an action plan for a European eHealth area, 2004 (available at http: europa.eu.int/eurlex/pri/en/dpi/cnc/doc/2004/com2004_0356en01.doc, accessed on 12 Jun, 2018)

Faiola, P., and Holdenb, R.J. (2018). Consumer Health Informatics: Empowering HealthyLiving-Seekers Through mHealth, Progressincardiovascular Diseases, 5 9, $479-486$

Fung, N. L. S., Jones, V. M., Bults, R. G. A., and Hermens, H. J., (2014). Guideline-based decision support for the mobile patient incorporating data streams from a body sensor network, in Wireless Mobile Communication and Healthcare (Mobihealth), 2014 EAI 4th International Conference on, 2014, 312-315.

Gardner, R. M., Overhage, J. M., Steen, E. B., Munger, B. S., Holmes, J. H., Williamson, J. J., \& Detmer, D. E. (2009). Core Content for the Subspecialty of Clinical Informatics. Journal of the American Medical Informatics Association, 16(2), 153-157.

Garmann-Johnsen, N. F., and Roar Eikebrokk, T. (2017). Dynamic capabilities in e-health innovation: implications for policies. Health Policy and Technology 6 (3): 292-301.

Hunt, D. L., Haynes,R.B., Hanna, S.E., and Smith, K. (1998). Effects of computer-based clinical decision support systems on physician performance and patient outcomes: a systematic review, Jama, 280 (15), 1998,1339-1346.

Ikram, R.R.R., Ghani, M.K.A., and Abdullah, N. (2015) An analysis of application of health informatics in Traditional Medicine: A review of four Traditional Medicine Systems, International Journal of Medical Informatics 84(11), 988-996

Jamshidi, P., Ghafari, M..Ahmad, A., Pahl, C. (2012). A Protocol for Systematic Literature Review on Architecture-Centric Software Evolution Research, Technical Report, LeroThe Irish Software Engineering Research Centre, Dublin City University, Oct. 2012.

Karim, S. and Bajwa, I. S. (2011). Clinical decision support system based virtual telemedicine, in Intelligent Human-Machine Systems and Cybernetics (IHMSC), 2011 International Conference on, 1, 16-21.

Kocbek, S., Cavedon, L., Martinez, D., Bain, C., Manus, C.M., Haffari, G., Zukerman, I., and Verspoor, K. (2016). Text mining electronic hospital records to automatically classify admissions against disease: Measuring the impact of linking data sources, Journal of Biomedical Informatics, 64, 158-167

Kuntagod, N. and Mukherjee, C. (2011). Mobile decision support system for outreach health worker, in e-Health Networking Applications and Services (Healthcom), 13th IEEE International Conference on, 2011, 56-59.

Lilholt , P.H., Jensena,M.H., Hejlesen, O.K. (2015). Heuristic evaluation of a telehealth system from the Danish TeleCare North Trial, International Journal of Medical Informatics, 84, 319-326

Mahmud, S., and Iqbal, R., and Doctor, F. (2016). Cloud enabled data analytics and visualization framework for health-shocks prediction, Future Generation Computer Systems, 65, 169-181 
Martínez-Pérez, B., de la Torre-Díez, I., López-Coronado, M., Sainz-de-Abajo, B., Robles, M., and García-Gómez, J.M. (2014). Mobile clinical decision support systems and applications: A literature and commercial review. J Med Syst. 38(1), 4

Miah, S.J., Hasan, J., and Gammack, J. G. (2016). On-Cloud Healthcare Clinic: An e-health consultancy approach for remote communities in a developing country, Telematics and Informatics, 34 (1), 311-322

Miah, S.J., Hasan, N., Hasan, R. and Gammack, J.G. (2017). Healthcare support for underserved communities using a mobile social media platform, Information Systems, $66,1-12$

Miah, SJ, Ahsan, K. and Msimangira, KAB. (2013). An Approach of Purchasing Decision Support in Healthcare Supply Chain Management, OPERATIONS AND SUPPLY CHAIN MANAGEMENT 6 (2), 43-53

Miah, SJ. (2008). An ontology based design environment for rural decision support, Unpublished PhD Thesis, Griffith University, QLD, Australia

Miah, SJ., Gammack, J., Hasan, N., Hasan, H. (2017). A Decision Support Framework for Public Healthcare: An Approach to Follow-up Support Service, Australasian Conference on Information Systems, Dec 3-5, 2017, Hobart, Australia, Available at: https://www.acis2017.org/wpcontent/uploads/2017/11/ACIS2017_paper_218_FULL.pdf, accessed on 23 July 2018.

Mosa, A. S. M., Yoo, I., and Sheets, L. (2012). A Systematic Review of Healthcare Applications for Smartphones, BMC Med Information Decision Making, 12 (67), 2-31

Nadri, H., Rahimi B., Timpka T., Sedghi S., (2017). The top 100 articles in the medical informatics: a bibliometric analysis. J Med Syst, 41 (10) 150

Nair, L.R., Shetty, S. D., and Shetty, S. D. (2018). Applying spark based machine learning model on streaming big data for health status prediction, Computers and Electrical Engineering, 65, 393-399

Nguyen, A., Mosadeghi, S., and Almarioa, C.V. (2017). Persistent digital divide in access to and use of the Internet as a resource for health information: Results from a California population-based study, International Journal of Medical Informatics, 103, 49-54

Nowell, L. S., Norris, J. M., White, D. E., \& Moules, N. J. (2017). Thematic Analysis: Striving to Meet the Trustworthiness Criteria. International Journal of Qualitative Methods, 16(1), 1609406917733847.

O'donoghue, J. and Herbert, J. (2012). Data management within mHealth environments: Patient sensors, mobile devices, and databases, Journal of Data and Information Quality (JDIQ). 4 (1): 5

Parveen, D. (2014). SMARTHealth India: development and field evaluation of a mobile clinical decision support system for cardiovascular diseases in rural India, JMIR mHealth uHealth, 2, (4), 2014, e54.

Phan, N., Dou, D., Wang, H., Kil, D., and Piniewski, B. (2017). Ontology-based deep learning for human behaviour prediction with explanations in health social networks, Information Sciences, 384, 298-313 
Queirósa, A., Cerqueira, M., Santos, M., and Rocha, P. (2017). Mobile Health to Support Ageing in Place: A Synoptic Overview, Procedia Computer Science, 121, 206-211

Rallapalli, S., Gondkar, RR, Ketavarapu, U. P. K. (2016). Impact of Processing and Analyzing Healthcare Big Data on Cloud Computing Environment by Implementing Hadoop Cluster, Procedia Computer Science, 85, 16 - 22

Ramesh, M. V., Anu, T. A., and Thirugnanam, H. (2012), An intelligent decision support system for enhancing an m-health application, in 2012 Ninth International Conference on Wireless and Optical Communications Networks (WOCN), 2012, 1-5.

Richardson, S., Mishurisb, R., O'Connella, A., Feldstein, D., Hessd, R., Smith, P., McCullagh, L., McGinn, T., and Mann, D. (2017). “Think aloud" and“Near live"usability testing of two complex clinical decision support tools, International Journal of Medical Informatics, 106, 1-8

Robinson, J. R., Valentine, A., Carney, C., Fabbri, D., and Jackson, G.P. (2014). Complexity of medical decision-making in care provided by surgeons through patient portals, journal of surgical research, $214,93-101$

Roman, L.C., Ancker, J.S., Johnson, S.B., and Senathirajah, Y. (2017) Navigation in the electronic health record: A review of the safety and usability literature, Journal of Biomedical Informatics 67, 69-79

Shin, D.H., Lee, S., and Hwang, Y. (2017). How do credibility and utility play in the user experience of health informatics services?, Computers in Human Behavior, 67, 292-302

Sun, Q., Wanga, S.N., Lib, S., and Zhoua, H. (2018) Local spatial obesity analysis and estimation using online social network Sensors, Journal of Biomedical Informatics 83,5462

Vaishnavi, V., and Kuechler, W. (2008). Design Science Research Methods and Patterns: Innovating Information and Communication Technology. Auerbach Publications, Boston, MA.

Valdez, A.C. and Ziefle, M. (2018). The users 'perspective on the privacy-utility trade-offs in health recommender systems, International Journal of Human-Computer Studies, 000 (2018) 1-14

Wang, X., Turner, L., and Scott, RE (2003). Technology solutions - saving the day?, in the proceedings of the 6th Annual Can Soc of Telehealth Conference, Halifax. Nova Scotia 5-7 Oct 2003

Webster, J. and Watson, R.T. (2002). Analysing the past to prepare for the future: writing a literature review, Management Information Systems Quarterly, 26(2), xiii-xxiii.

Yoshiura, V. T., Yamada, D.B., Pellison, F.C., de Lima, I.B., Damiand, I.P. M., ...et al. (2018). Towards a health observatory conceptual model based on the semantic web, Procedia Computer Science, 138, 131-136

Copyright: (C) 2019 Miah, Shen, Lamp, Kerr \& Gammack. This is an open-access article distributed under the terms of the Creative Commons Attribution-NonCommercial 3.0 
Australia License, which permits non-commercial use, distribution, and reproduction in any medium, provided the original author and AJIS are credited.

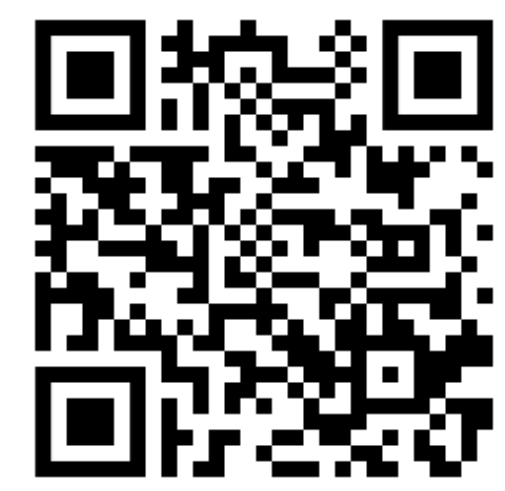

